\title{
Evaluation of Safety in Cesarean Myomectomy
}

\author{
${ }^{1}$ Sabnam S Nambiar, ${ }^{2}$ S Ajith, ${ }^{3}$ Vidya Prabhu, ${ }^{4}$ Beena George
}

\begin{abstract}
Objectives: Cesarean myomectomy (removal of fibroids during cesarean section) prevents an additional surgery, the cost, associated complications, and the physical and psychological trauma. However, there is risk of increased bleeding. Nevertheless, many centers practice it taking optimum precautions. The aim of our study was to compare cesarean myomectomy patients in those women who underwent cesarean section without fibroid removal for (a) blood loss, fall in hemoglobin, blood transfusion requirement; (b) intraoperative and postoperative complications; and (c) duration of hospitalization.
\end{abstract}

Materials and methods: We retrospectively studied medical records of cesarean sections done in our institution for women within the past 5 years. A total of 76 patients had documented fibroids, of whom 37 underwent concurrent myomectomy and 39 did not. Data were analyzed using Pearson's Chi-square test for categorical variables and student $t$ test for continuous variables with threshold of significance $p<0.05$.

Results: No significant difference was found in blood loss and intraoperative complications. A small increase was seen in febrile morbidity in myomectomy group, however, with no resultant increase in hospitalization.

Conclusion: Cesarean myomectomy does not cause increased morbidity. Moreover, it saves the mother an additional surgery of interval myomectomy provided proper selection of cases, adequate preoperative and intraoperative preparedness, and caution are taken into consideration.

Keywords: Blood loss, Cesarean myomectomy, Fibroid, Hospital stay.

How to cite this article: Nambiar SS, Ajith S, Prabhu V, George B. Evaluation of Safety in Cesarean Myomectomy. J South Asian Feder Obst Gynae 2016;8(2):136-139.

Source of support: Nil

Conflict of interest: None

Date of received: 9 Jan 2016

Date of acceptance: 18 Feb 2016

Date of publication: April 2016

\section{INTRODUCTION}

Cesarean myomectomy refers to the removal of fibroids during cesarean sections. Fibroids are benign neoplasms

\footnotetext{
${ }^{1,3}$ Assistant Professor, ${ }^{2}$ Professor, ${ }^{4}$ Associate Professor

${ }^{1-4}$ Department of Obstetrics and Gynaecology, Pariyaram Medical College, Kannur, Kerala, India
}

Corresponding Author: Sabnam S Nambiar, Assistant Professor, Department of Obstetrics and Gynaecology, Pariyaram Medical College, Kannur, Kerala, India, Phone: +918606868902 e-mail: sabnamsn@rediffmail.com of uterine musculature causing problems like menstrual disturbances, pain, infertility, abortions, dysfunctional or obstructed labor, and postpartum hemorrhage.

Myomectomy at the time of cesarean delivery was feared because of the risk of hemorrhage. This had deprived numerous women from the opportunity of freedom from this malady at the same sitting of cesarean section forcing them either to continue suffering from the problems due to fibroids or to endure another surgery in the name of treatment. If fibroids can be removed concurrently with cesarean section, it could reduce the intraop complications (like injury due to adhesions, anesthesia complications, bleeding) and postoperative complications associated with an additional surgery.

Studies are now under way and some are complete, which have shown encouraging results favoring concurrent myomectomy during cesarean section without the dreaded complication of significant hemorrhage.

A retrospective study was performed to determine whether myomectomy at the time of cesarean delivery leads to an increased incidence of intrapartum and shortterm postpartum complications. They were compared against a group for which fibroid removal was omitted where emergency cesarean section had been performed.

\section{REVIEW OF LITERATURE}

Myomectomy at the time of cesarean delivery had been earlier considered a formidable procedure with the lurking threat of life-threatening hemorrhage. With the exception of small, pedunculated fibroids, most of the leading obstetrics textbooks advise against myomectomy during cesarean delivery due to theoretical risks of intractable hemorrhage and increased postoperative morbidity. ${ }^{1,2}$ In the medical literature, however, there are few studies that directly address this controversy. There are some case series and anecdotes that give mixed results. ${ }^{3-8}$

Across the world many institutions have, however, started embarking on the procedure cautiously lured by the proposed advantages. In an attempt to define the risks of myomectomy during cesarean delivery, we look at the past 5-year experience at our institution with the procedure.

\section{OBJECTIVES}

To determine whether myomectomy at the time of cesarean delivery leads to an increased incidence of hemorrhage and perioperative morbidity, and to identify subgroups that may be at a higher risk of developing intrapartum hemorrhage. 
These women fulfilled the following criteria: (1) Documented fibroid uterus during the index pregnancy by antepartum ultrasound or by intraoperative findings; (2) delivery by cesarean section; (3) admission and postpartum hematocrits in the database; (4) no evidence of antenatal bleeding (e.g., from placenta praevia or abruption); (5) no other procedures at the time of cesarean delivery besides myomectomy (e.g., cystectomy, myolysis, or planned hysterectomy); and (6) no comorbid conditions with evidence of coagulopathy.

Characteristics compared include age, parity, gestational age at delivery, type of cesarean performed, and size and location of fibroid. In the myomectomy group, the size of the excised fibroid was obtained from the pathology reports and operation notes.

Primary outcomes analyzed were change in hematocrit, postpartum fever, operative time, and duration of hospitalization. Hemorrhage was analyzed based on blood loss, fall in hemoglobin from preoperative value to the postoperative value, or the need for intraoperative transfusion. Fever was defined as postoperative temperature greater than or equal to $37.6^{\circ} \mathrm{C}$.

\section{MATERIALS AND METHODS}

The medical records of cesarean sections done at our institution on women with fibroids were studied.

Sample size was determined based on the average number of antenatal women attending the antenatal clinic over the previous 3 years who had undergone cesarean section for various indications. A total of 76 cases were found over 5 years, of which in 37 women myomectomy had been done concurrently with cesarean section and 39 in which myomectomy had been omitted.

\section{PROCEDURE}

The women in either group had given informed consent for cesarean section alone or for cesarean along with myomectomy. In the myomectomy group, in case of fibroids larger than $4 \mathrm{~cm}$, prophylactic uterine artery ligation had been done after cesarean before starting myomectomy. The blood loss is routinely measured in our institution by weighing the soaked pads and from the collection in the suction drain. Preoperative and postoperative hemoglobin had been measured and the fall in hemoglobin was recorded as mentioned in Table 3 and Graph 3. The number of units of blood transfusion, if required, any intraop or postop complication was duly noted and documented. The duration of hospital stay Table 6 and Graph 6 was also documented (after excluding prolongation of stay required for the sake of the baby).

All data were analyzed using Pearson's chi-squared test for categorical variables and student $t$ test for continuous variables. The threshold of significance was defined as $\mathrm{p}<0.05$.

\section{RESULTS}

The demographic variables of age; socioeconomic status; previous mode of delivery; and methods of diagnosis of fibroid average number, type, location, and size were found comparable in the two groups possibly since the women came from a common indigenous background. There had been no incidence of red degeneration of fibroid in either group.

The distribution of indications for cesarean being obstetric or fibroid per se in either group had also been comparable.

On analysis of outcomes no difference was found in estimated blood loss (Graphs 1 to 3), need for transfusion (Graphs 4 and Table 4) or intraoperative injuries. Statistically significant increase was seen in febrile morbidity in myomectomy group (Table 5 and Graph 5) which however did not translate into a prolonged hospital stay (Table 6 and Graph 6). In other words they were easily controlled with supportive therapy (hydration, antibiotics).

(1) Estimated blood loss

Table 1: Estimated blood loss during surgery

\begin{tabular}{llll}
\hline Estimated blood loss & No myomectomy & Myomectomy & Total \\
\hline$<500 \mathrm{~mL}$ & 32 & 29 & 61 \\
$500-1000 \mathrm{~mL}$ & 6 & 8 & 14 \\
$>1000 \mathrm{~mL}$ & 1 & 0 & 1 \\
\hline Total & 39 & 37 & 76
\end{tabular}

Chi-square $=1.382 ; p=0.501$

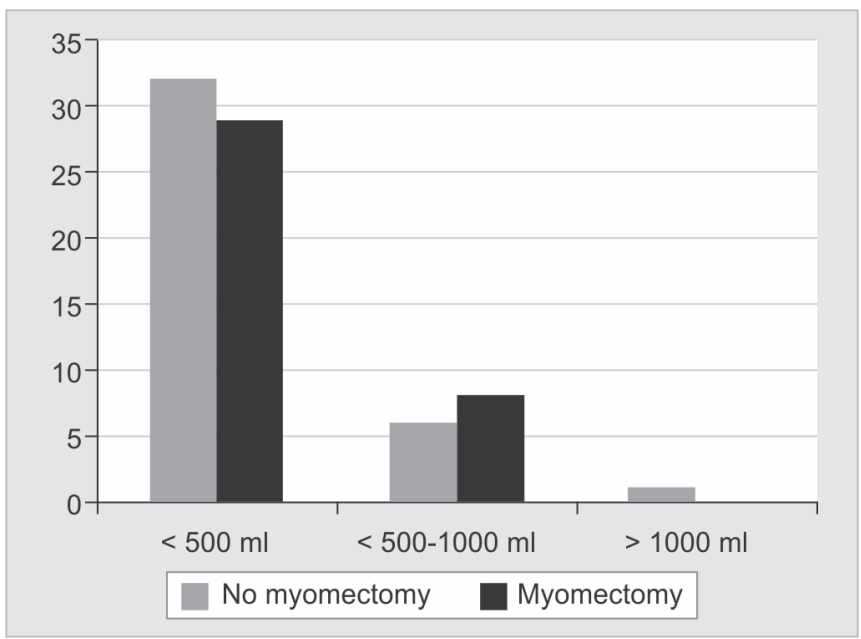

Graph 1: Estimated blood loss during surgery

No significant decrease in blood loss in either group (2) Number of blood units transfused

Table 2: Number of blood units transfused

\begin{tabular}{llll}
\hline $\begin{array}{l}\text { Units of blood } \\
\text { transfused }\end{array}$ & No myomectomy & Myomectomy & Total \\
\hline 0 & 34 & 32 & 66 \\
1 & 3 & 3 & 6 \\
2 & 2 & 1 & 3 \\
$3-4$ & 0 & 1 & 1 \\
\hline Total & 39 & 37 & 76 \\
\hline
\end{tabular}

Chi-square $=1.342 ; p=0.719$ 


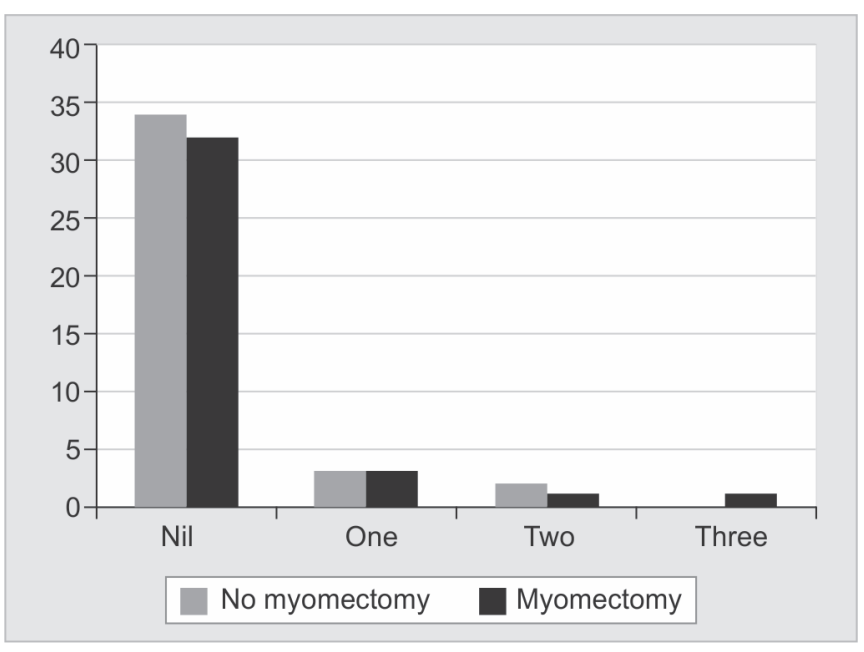

Graph 2: Number of blood units transfused

There was no increase in units of blood transfused in the myomectomy group. On the contrary, one patient in nonmyomectomy group had increased need for transfusion. It was, however, due to bleeding from inferior epigastric artery.

(3) Postoperative fall in haemoglobin values

Table 3: postoperative fall in haemoglobin values

\begin{tabular}{llll}
\hline Fall in $\mathrm{Hb}(\mathrm{g} \%)$ & No myomectomy & Myomectomy & Total \\
\hline$<1.5$ & 32 & 29 & 61 \\
1.6 or more & 7 & 8 & 15 \\
\hline Total & 39 & 37 & 76 \\
\hline
\end{tabular}

Chi-square $=0.162 ; p=0.454$

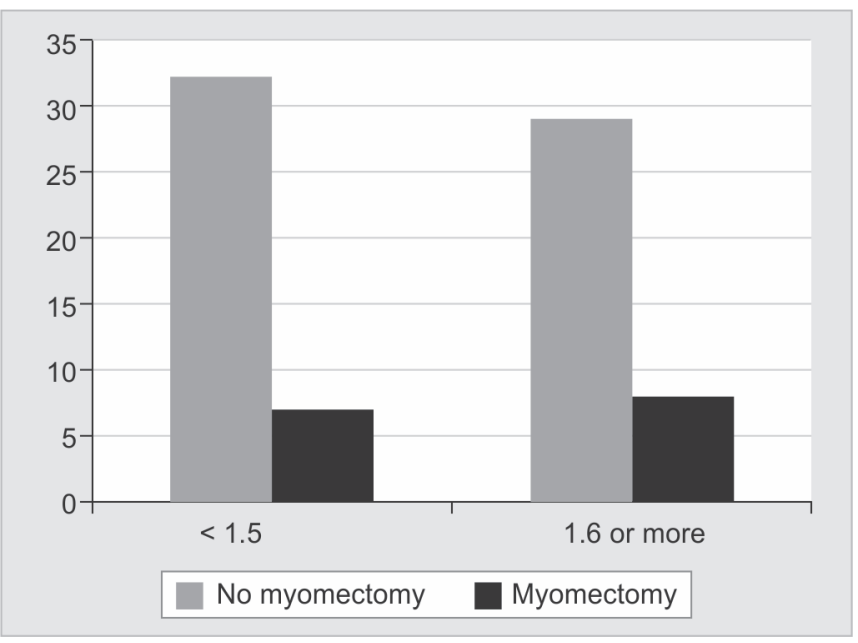

Graph 3: Postoperative fall in haemoglobin values

There was no significant increase in hemoglobin fall in the myomectomy group.

(4) Incidence of intraoperative injuries

Table 4: incidence of intraoperative injuries

\begin{tabular}{llll}
\hline Intraop inj & No myomectomy & Myomectomy & Total \\
\hline Absent & 38 & 36 & 74 \\
Present & 1 & 1 & 2 \\
\hline Total & 39 & 37 & 76
\end{tabular}

Chi-square $=0.001 ; p=0.740$

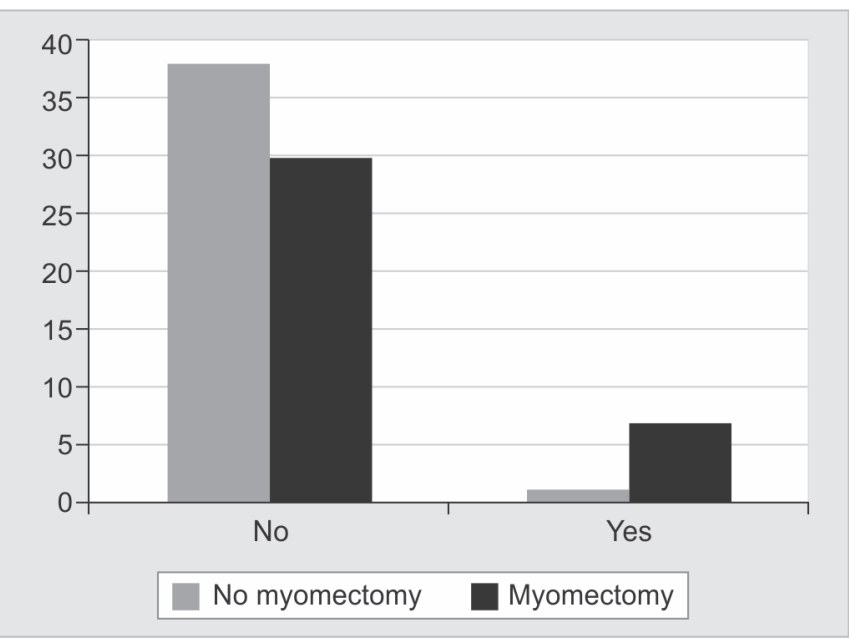

Graph 4: Incidence of intraoperative injuries

There was no significant increase in the incidence of intraoperative injuries in the myomectomy group.

(5) Incidence of febrile morbidity in postoperative period Table 5: Incidence of febrile morbidity in postoperative period

\begin{tabular}{llll}
\hline Postop fever & No myomectomy & Myomectomy & Total \\
\hline No & 38 & 30 & 68 \\
Yes & 1 & 7 & 8 \\
\hline Total & 39 & 37 & 76 \\
\hline
\end{tabular}

Chi-square $=5.392 ; p=0.023$

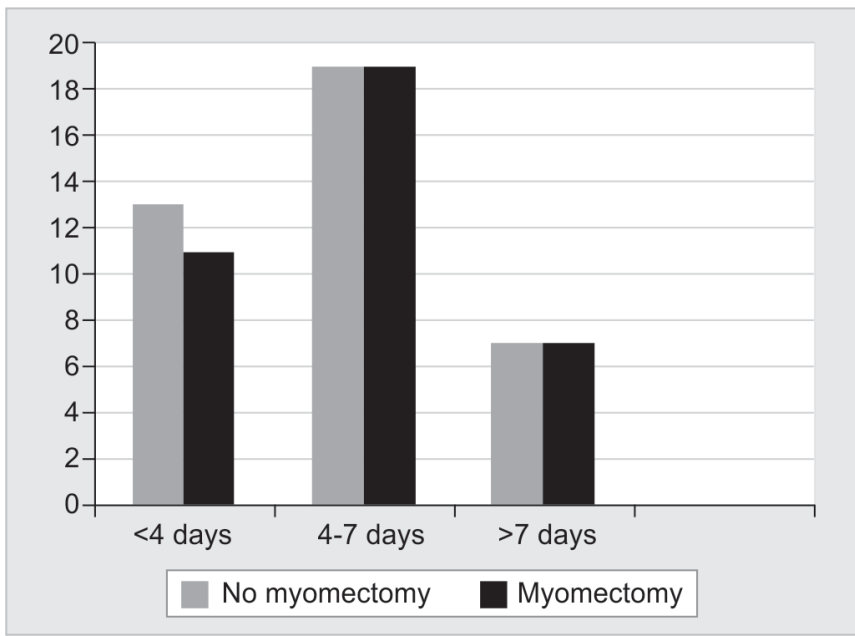

Graph 5: Incidence of febrile morbidity in postoperative period

There was a significant increase in febrile morbidity in the myomectomy group. However, the cases included respiratory and urinary tract infections, which could be treated easily and also did not prolong hospital stay in the patients concerned.

(6) Number of days of hospital stay

Table 6: Number of days of hospital stay

\begin{tabular}{llll}
\hline Hospital stay & No myomectomy & Myomectomy & Total \\
\hline$<4$ days & 13 & 11 & 24 \\
$4-7$ days & 19 & 19 & 38 \\
$>7$ days & 7 & 7 & 14 \\
\hline Total & 39 & 37 & 76 \\
\hline
\end{tabular}

Chi-square $=0.114$ 


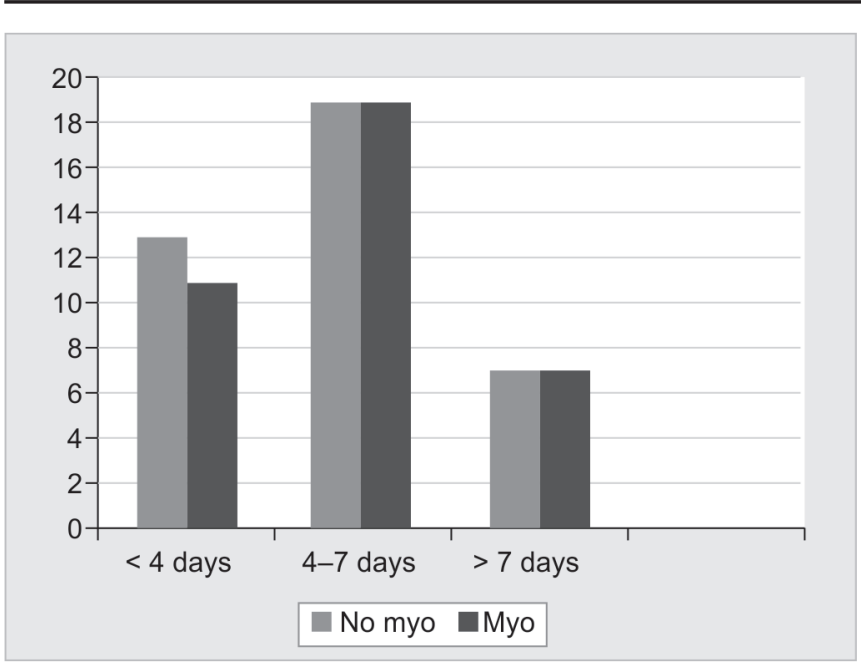

Graph 6: Number of days of hospital stay

$p=0.945$, which is not significant statistically. In either group, prematurity and neonatal complications like physiological jaundice and phototherapy accounted for hospital stay prolonged to 7 or more days.

\section{DISCUSSION}

The numerous problems caused by fibroids in nonpregnant individuals as well as in their ensuing pregnancies are cause enough for their removal, more so in a developing country like ours where an interval myomectomy would only add economic woes to the physical and mental trauma endured by the patient.

Removal of fibroids can have the following benefits apart from the cost effectiveness of the procedure:

- Prevent injuries due to adhesions in subsequent surgeries.

- Prevent menstrual abnormalities, complications in subsequent pregnancies due to fibroids, as earlier mentioned.

- A lower segment fibroid if removed helps in putting a lower segment incision and possible trial of labor in the next pregnancy. ${ }^{9}$

- Scar integrity in cesarean myomectomy found to be better than that of interval myomectomy as documented by ultrasound subsequently. ${ }^{10}$

The results of our study showed that myomectomy done with caesarean section did not increase the rate of haemorrhage as seen from Tables 1 to 3 . Table 4 and Graph 4 indicate that there was no increase in intraoperative complications in the myomectomy group.

\section{CONCLUSION}

In properly selected cases, myomectomy done during cesarean section does not increase the morbidity or mortality rate. Proper caution has to be, however, exercised by ensuring adequate availability of blood for transfusion, experienced surgeons able to detect and tackle intraop complications, use of bilateral uterine artery ligation, ${ }^{11}$ and electrocautery ${ }^{10}$ in large fibroids.

The advantages of caesarean myomectomy as mentioned earlier could compensate for the minor increase in febrile morbidity (Table 5 and Graph 5) in the myomectomy group .

Nevertheless, large randomized multicenter trials and studies to follow up long-term obstetric consequences may still be required before the final word could be said!

\section{ACKNOWLEDGMENTS}

Authors are indebted to God Almighty and all our colleagues and family members who have played an immeasurable role in the completion of our study.

\section{REFERENCES}

1. Depp R. Cesarean delivery. In: GabbeSG, NiebylJR, Simpson JL, editors. Obstetrics: Normal and problem pregnancies. 4th ed. New York: Churchill Livingstone; 2002. p. 599.

2. Cunningham FG, Gant NF, Levenok KJ, Gilstrap LC, Hauth JC, Wenstrom KD, editors. Chapter 35: Abnormalities of the reproductive tract. In: Williams Obstetrics. 21st ed. New York: McGraw Hill; 2001. p. 930.

3. Michalas SP, Oreopoulou FV, Papageorgiou JS. Myomectomy during pregnancy and Cesarean section. Hum Reprod 1995 Jul;10(7):1869-1870.

4. Hasan F, Arumugam K, Sivanesaratnam V. Uterine leiomyomata in pregnancy. Int J Gynecol Obstet 1991 Jan;34(1): 45-48.

5. Ortaç F, Güngör M, Sönmezer M. Myomectomy during cesarean section. Int J Gynecol Obstet 1999 Dec;67(3):189-190.

6. Burton CA, Grimes DA, March CM. Surgical management of leiomyomata during pregnancy. Obstet Gynecol 1989 Nov;74(5):707-709.

7. Ehigiegba AE, Ande AB, Ojobo SI. Myomectomy during cesarean section. Int J Gynecol Obstet 2001 Oct;75(1): 21-25.

8. Kwawukume EY. Cesarean myomectomy. Afr J Reprod Health 2002 Dec;6(3):38-43.

9. Sapmaz E, Celik H, Altungul A. Bilateral ascending uterine artery ligation $v s$ tourniquet use for hemostasis in cesarean myomectomy. A comparison. J Reprod Med 2003 Dec;48(12): 950-954.

10. Cobellis L, Florio P, Stradella L, Lucia ED, Messalli EM, Petraglia F, Cobellis G. Electro-cautery of myomas during Cesarean section - two case reports. Eur J Obstet Gynecol Reprod Biol 2002 Apr 10;102(1):98-99.

11. Omar SZ, Sivanesaratnam V, Damodaran P. Large lower segment myoma-myomectomy at lower segment Cesarean section-a report of two cases. Singapore Med J 1999 Feb; 40(2):109-110. 